\title{
BI for the Invisible University
}

Two years ago in Dallas the ALA Library Instruction Round Table heard Dr. K. Patricia Cross say, ". . . some of our richest learning experiences occur not in organized classes, but in self-directed learning that is pursued solely because the learner wants to know." 1 Investigation revealed that, in fact, ninety percent of all adults engage in some type of learning activity in a year and seventy-three percent of those projects are self-guided. ${ }^{2}$ Although not formally affiliated with an institution of higher learning, these students, Ronald Gross suggests, are part of an "invisible university," the network of learning opportunities and resources available to independent learners. ${ }^{3}$

Recognizing that libraries are a major component in this network and that these "unaffiliated" students may never have been exposed to any library orientation or instruction, the GardnerHarvey Library and the Office of Continuing Education at Miami University-Middletown (MUM) initiated a non-credit course titled "Your Other Education: Library Lessons for Lifelong Learning." This course is a new element in an active bibliographic instruction program that includes teaching basic skills to pre-college students and to freshmen, conducting course-related instruction in several disciplines, and producing printed guides to the library and to various subjects. While those activities reflect the campus curriculum, "Your Other Education" does not. This course is geared toward independent learners, who have a multiplicity of motivations for learning, who use many different resources and services to acquire knowledge, and who work at an individually determined pace.

"Your Other Education" was first taught by the campus librarian in the fall of 1980 , meeting once a week in two-hour sessions for six weeks. Students earned 1.2 continuing education units (CEUs) for successful completion. Publicity for the course was carried out by the Office of Continuing Education. The course appeared in their fall catalog along with Aerobic Dancing, Math

\footnotetext{
${ }^{1} \mathrm{~K}$. Patricia Cross, "Libraries in the Learning Society." Paper presented at the Annual Conference of the American Library Association, Dallas, Texas, 26 June 1979, p. 4.

${ }^{2}$ Barry Heermann, Cheryl Coppeck Enders, and Elizabeth Wine (guest editors), Serving Lifelong Learners (San Francisco: Jossey-Bass, 1980), p. vii.

${ }^{3}$ Ronald Gross, The Lifelong Learner (New York: Touchstone, Simon and Schuster, 1977), p. 87.
}

Without Fear, Joy of the Arts, and Leadership Theory for Newly Registered Nurses. A detailed brochure on "Your Other Education" was also prepared and mailed to approximately two hundred holders of community borrowing cards from the Gardner-Harvey Library. Multiple copies of the brochure were placed in local public libraries and were sent to businesses and to the Greater Cincinnati Library Consortium for distribution. All registration was handled by the Office of Continuing Education.

Students were asked to purchase two textbooks, The Lifelong Learner by Ronald Gross (New York: Touchstone, Simon and Schuster, 1977) and Finding Facts Fast by Alden Todd (Berkeley: Ten Speed Press, 1979). The books were selected for their readability and their emphasis on the use of libraries for self-directed learning as opposed to the "how-to-use-theacademic-library-to-write-a-term-paper" approach of many guides. Correspondence with both authors proved very fruitful in the planning of the course.

In the first session the course was introduced with a discussion of lifelong learning and the roles of libraries and information-seeking. Students were surveyed by means of a questionnaire that explored occupation, education, hobbies/special interests, library use, and age. It was a diverse population, ranging in age from mid-forties to over sixty. Some students had full time jobs outside the home, some were retired, and some were homemakers. All students had completed high school and experience in college ranged from a few courses to completed master's degrees.

To the question, "At any time during your formal education did you receive instruction in the use of libraries?" the negative response was one hundred percent. Students had participated in the last two years in a variety of educational activities such as auditing university courses, completing non-credit courses, engaging in private lessons, and attending workshops, seminars, and professional conferences. They also had studied independently using commercially planned and self-planned programs. One student had planned a learning program for others. All students held cards from their local public library; twenty percent held cards from GardnerHarvey Library.

Special interests of the students included reading, art, travel, genealogy, church history, gambling, interior design, computers, and Chinese 
culture. These were fully matriculated students of the invisible university!

They were also given a pre-test to determine their prior knowledge of library resources. The test included a matching section on information and library resources, a true/false section on libraries and lifelong learning, and short answer sections on the card catalog and the Reader's Guide. The highest score on the pre-test was eighty-three percent; the lowest, sixty-five.

Session II covered the "lingo" of libraries, including history and types, major schemes of organization, and types and characteristics of reference materials. The next three sessions were subject oriented, covering financial information sources (Making Sense of $\$ \$ \$$ and $\varnothing \varnothing()$ ), legal and medical information (Helping your Helpers), and employment and recreation (At Work and At Play). In the final session, "Wrap It Up and Take It Home," students were presented tips on planning, organizing, and documenting a learning project and on creating a home reference library. On that last night they also took a post-test, each student revealing improvement of four to fifteen percentage points.

There were many reasons for planning and executing "Your Other Education: Library Lessons for Lifelong Learning." A potential student (who did take the course) suggested that library utilization might make a good topic for a continuing education course. The librarian, to whom that suggestion was made, had had sufficient experience with "fifty-minute stands" that she wanted and needed the experience of teaching library skills to a group that met over a period of time. But it was during her background research into lifelong learning that the true rationale for such a course became apparent. The editors of Serving Lifelong Learners, number twenty nine in the Jossey-Bass New Directions for Community Colleges series, say, "Most learning is simply not under our (the community colleges') auspices," and that the institutions "need to be less preoccupied with control and much more concerned with supporting and guiding students in learning pursuits." 4 On that assumption, teaching library and bibliographic skills to non-affiliated learners is an appropriate component of an academic library's instruction program and the campus' continuing education unit may be the most effective channel for implementation.-Virginia Ellis Palmer.

${ }^{4}$ Heerman, Enders, and Wine, Serving Lifelong Learners, p. viii.

Editor's Note: Virginia Palmer is head regional campus librarian at Miami University-Middletown, Ohio.

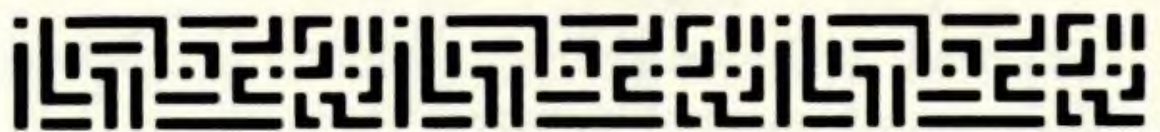

\author{
Fallacies of \\ Librarianship
}

A British librarian of many talents and much experience has devised the following list of erroneous but commonly-held beliefs maintained by some library professionals. The list has recently been published by New Library World, a London publication.

1. Users can find their own way around a library.

2. Users are completely helpless at all stages of library use.

3. Gift books are free.

4. Cooperation between libraries, of whatever kind, saves money.

5. Holdings are more important than service.

6 . The case for well-funded libraries is selfapparent.

7. A library that receives no complaints is a good library.

8. Library education is a useful preparation for library practice.

9. A research library should give the unknown needs of the future priority over the known needs of the present.

10. The catalog is the key to the library.

11. Interlibrary borrowing is expensive.

12. Interlibrary borrowing is a cheap substitute for acquisition.

13. Interlibrary borrowing is no substitute for acquisition.

14. The distance between a lending and a borrowing library affects the speed of supply.

15. It is possible to devise a classification scheme that organizes knowledge in a coherent, useful, and intelligible way that is and will remain acceptable.

16. Existing classification schemes can be improved by local modifications.

17. No system devised for one library can be adopted by any other library.

18. A love of books is a useful prerequisite for a librarian.

19. All that is needed to improve a library service is more money and more staff.

20. A library building that wins a prize for architecture is functional.

If $C \mho R L$ News readers wish to add further fallacies to the list, or if something has been included which perhaps should not have been, write George M. Eberhart, ACRL/ ALA, 50 E. Huron Street, Chicago, IL 60611.

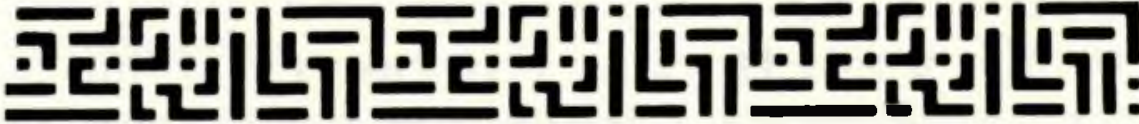

